\title{
EVOLUÇÃO ESTRUTURAL DO PLATÔ MARGINAL DA GUINÉ E SUA RELAÇÃO COM A FORMAÇÃO DO OCEANO ATLÂNTICO CENTRO-EQUATORIAL
}

\author{
MARTA MARINHO* e JEAN MASCLE*
}

\begin{abstract}
Offshore West Africa the Guinean Marginal Plateau facing the Caribbean area lies between the Central Atlantic and the South Atlantic. It constitutes a very important piece in order to fit continents around the Atlantic. In 1983 an oceanographic cruise conducted off Guinea brought news geological and geophysical data; they have been used in this study to. propose a detailed stratigraphy and to construct a structural sketch of the region. The evolution of the area can be summarized in two phases: I. A first one (in Jurassic times) corresponds to the creation of the western Guinea margin, resulting from the separation of North America from Africa. II. During a second phase (in Cretaceous times) part of the former margin was submitted to a tectonic reactivation due to shear stresses along Guinea Fracture Zone, when the South Atlantic started to open. The results of this last phase created, south of the Guinea Plateau, a complex structural system including emplacement of volcanic piles.
\end{abstract}

INTRODUÇÃo A margem continental: da África ocidental (Fig. 1) apresenta duas direções morfológicas importantes: a primeira (NNE-SSW) corresponde ao trecho que vai da Mauritânia ao norte da Guiné; o segundo trecho; de direção NNW-SSE, compreende Serra Leoa e Libéria.

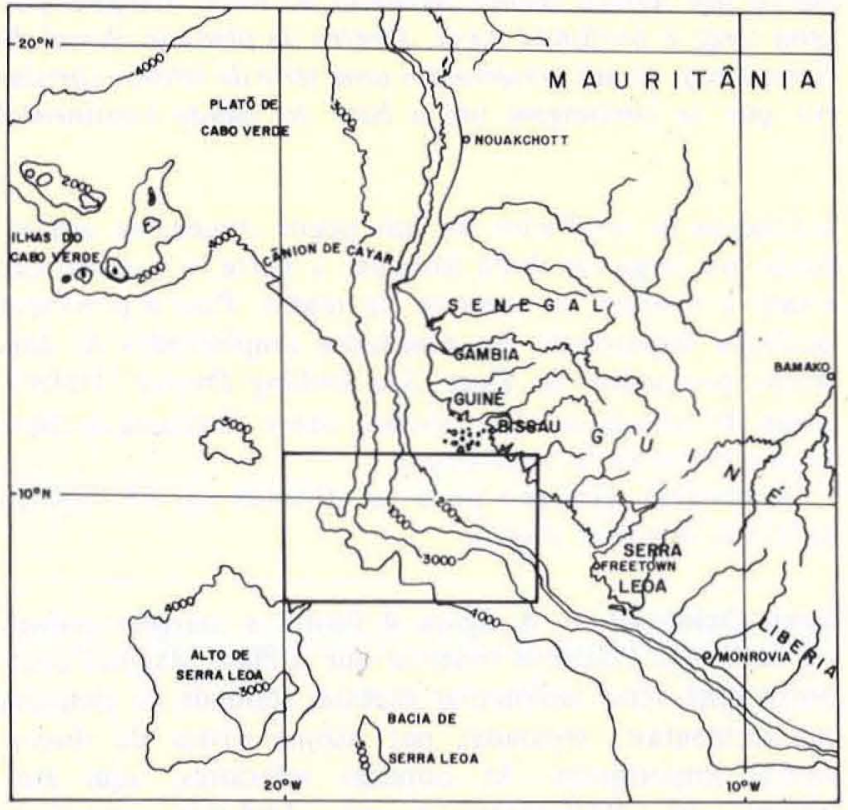

Figura 1 - Localização da área estudada (retângulo central) em um mapa batimétrico atual da margem oeste africana entre a Mauritânia e a Libéria (extraido de um mapa, GEBCO-General Bathymetric Chart of the Oceans, Central Atlantic, Canadian Hydrographic Service e UNESCO, 1982). Batimetria em metros

Entre esses dois setores encontra-se o Platô-Marginal da Guiné (Egloff 1972), que forma um grande terraço submarino, atingindo $200 \mathrm{~km}$ de extensão e até $3.000 \mathrm{~m}$ de profundidade. Esse platô é limitado a oeste por um talude continental (em continuidade com o talude do Senegal) pas- sando gradualmente à planície abissal da Gâmbia. O limite meridional do platô, ao contrário, apresenta-se sob forma de um talude escarpado, cuja direção é de uma maneira geral E-W, passando bruscamente à planície abissal de Serra Leoa.

Este último escarpamento, associado por Krause (1964) à Zona de Fratura da Guiné, coincide com uma série de fraturas dispostas em escalonamento, podendo atingir até a 'extremidade do Platô da Guiné. Esse sistema de falhas se prolonga dentro da planície abissal de Serra Leoa por meio de uma série de montes submarinos, os quais, nos mapas magnéticos, correspondem a anomalias importantes.

Apesar dos vários estudos efetuados nessa região, pouco se conhece de sua estratigrafia e de sua evolução estrutural. Alguns documentos sísmicos existentes (Templeton 1971, Lehner \& De Ruiter 1977, Uchupi et al. 1976, Emery et al. 1975) permitem distinguir sob o Platô Marginal da Guiné uma espessa série sedimentar que recobre rochas paleozóicas. Outros documentos de refração sísmica (Sheridan et al. 1969) efetuados ao sul da região possibilitam a compreensão da estrutura profunda da bacia de Serra Leoa. Recentemente, Jones \& Mgbatogu (1982) publicaram mapas gravimétricos e magnéticos do setor. Os modelos da estrutura crustal propostos por esses autores indicam, ao sudoeste do Platô da Guiné, a presença de uma crosta de tipo intermediário, que caracteriza a passagem entre o domínio continental e o domínio oceânico. Essa transição no setor meridional opera-se de uma maneira muito mais brusca sem a presença de uma crosta'de tipo intermediário.

Nas diversas tentativas de reconstrução do Oceano Atlântico (Bullard et al. 1965, Le Pichon \&Fox 1971, Olivet et al. 1984), a margem guineana situa-se em uma zona de transição entre o Oceano Atlântico Norte e o Oceano Atlântico Sul. O mau conhecimento da evolução do Caribe e, de uma maneira geral, do Atlântico Central dificulta a busca da região homóloga ao Platô da Guiné (do lado oposto do Atlântico). Por outro lado, nas reconstituições dos continentes anteriores, a margem meridional da Guiné encontra-se em frente a um vazio oceânico enquanto a zona transformante da Guiné é conectada a uma zona de fratura que passaria pela Flórida, na América do Norte.

* Université Pierre et Marie Curie (Paris VI), Laboratoire de Geodynamique Sous - Marine de Villefranche-sur-Mer. B.P. 48, 06230 , Villefranche-sur-Mer, France 
Com o objetivo de esclarecer essa falta de precisão em relação à reconstituição dessa área, foi realizado este estudo, cuja maioria dos dados são provenientes de uma campanha oceanográfica (chamada Equamarge) efetuada em 1983 no largo da Guiné (Fig. 2). Os documentos obtidos englobam 18 linhas de reflexão sísmica, utilizando como fonte principalmente um canhão a água (water-gun), e uma série de amostras sistemáticas (dragagens e amostras em testemunho), assim como 18 perfis batimétricos e magnéticos. Os resultados obtidos neste estudo serão aqui apresentados de maneira sintética.

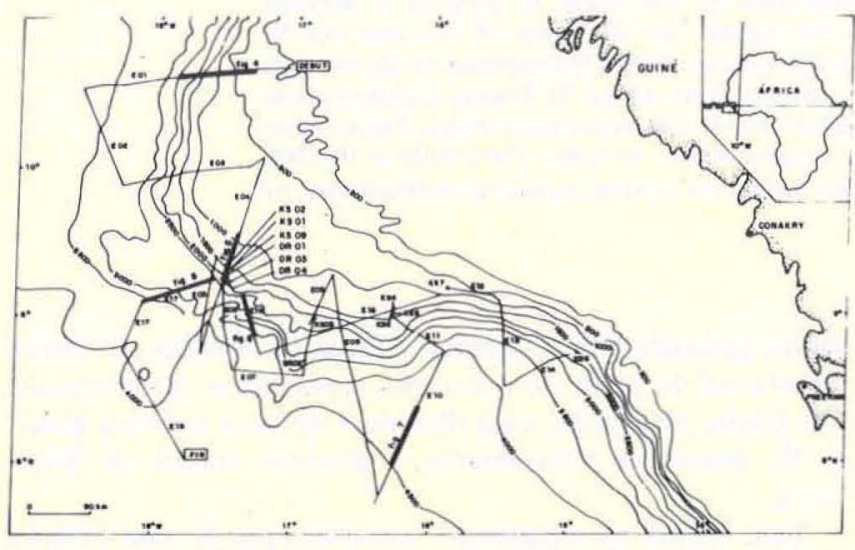

Figura 2 - Plano de posição das linhas sísmicas Equamarge, registradas em 1983 no largo da Guiné, com a posição das estações de dragagem e das amostras em testemunho $(K S$, amostras em testemunho; $D R$, dragagens). Os registros sismicos foram obtidos utilizando como fonte um canhão a água (water-gun). Os dados foram obtidos a bordo do navio oceanográfico Le Suroit. Os extratos dos perfis sismicos ilustrados nas figuras de 4 a 8 são sublinhados nesse plano

BATIMETRIA O mapa batimétrico proposto nesse trabalho (Fig. 3) reúne os resultados da campanha Equamarge e de outros cruzeiros anteriores, e valores provenientes da General Bathymetric Chart of the Oceans (GEBCOUNESCO 1982).

De uma maneira geral, a principal característica morfológica da região consiste no contraste entre o setor ocidental, cujo talude possui uma direção NNE-SSW, e o setor meridional, que apresenta um talude escarpado de direção E-W. Este último, comporta igualmente uma série de relevos submarinos mais ou menos circulares, que são alinhados paralelos à margem continental e se estendem dentro da planície abissal, atingindo até a base do talude continental.

No mapa proposto notamos também a presença de um setor intermediário ao sudoeste da região. Nesse último setor observamos a existência de dois escarpamentos que limitam um terraço topográfico menor, separado do Platô Marginal propriamente dito por uma bacia sedimentar com uma forma mais ou menos triangular.

ESTRUTURA E ESTRATIGRAFIA No estudo da estratigrafia sísmica, as atribuições cronológicas dos diversos horizontes acústicos foram feitas por correlação com outras linhas sísmicas inéditas. Essas correlações são apoiadas no resultado sintético de alguns poços de perfuração relativamente próximos. Para o Platô Marginal da Guiné,

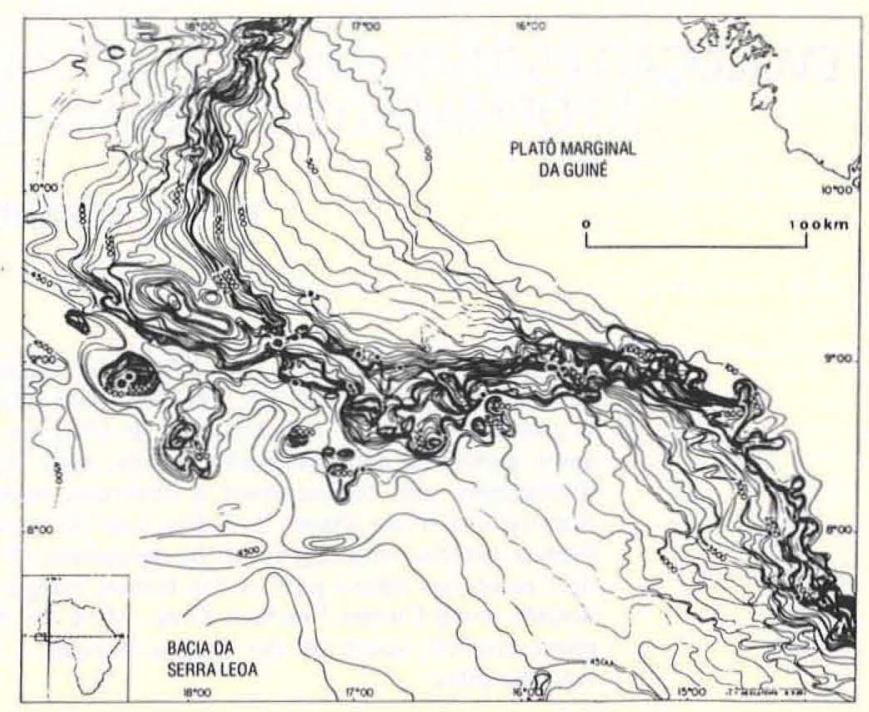

Figura 3 - Batimetria detalhada (em metros) da margem continental guineana. Este mapa foi confeccionado utilizando dados do GEBCO, Projeto Equamarge e de outras linhas anteriores inéditas. Notamos o contraste entre os três setores: a oeste, o talude é largo e entrecortado por vários canais e canyons; ao sul, o Platồ é limitado por um talude escarpado de direção $E-O ; e$, entre esses dois setores, observamos um terraço menor separado do Platô Marginal por uma larga e profunda bacia. Dentro da planicie abissal de Serra Leoa, ao sul, observamos uma série de relevos circulares que se prolongam até a base do talude continental

utilizamos os resultados de dois poços comerciais: um, situado no largo do delta Bissagos, a norte, e o outro em frente a Conacri, a sudoeste da região. Para a província oceânica dispusemos dos resultados simplificados de dois poços profundos do Deep Sea Drilling Project (DSDP), sítios 367 (Bacia do Cabo Verde), 366 e 13 (Bacia de Serra Leoa e Elevação de Serra Leoa).

A margem guineana pode ser dividida em três setores distintos, descritos abaixo.

Setor Ocidental A figura 4 ilustra a margem ocidental da Guiné. Podemos observar que o Platô Marginal comporta uma série sedimentar espessa, formada de camadas sub-horizontais, separadas por alguns níveis de discordância importantes. As camadas inferiores, aqui atribuídas ao Eocretáceo e ao Jurássico, mostram traços de falhas profundas. São separadas das camadas superiores por um paleotalude formado durante o NeoCretáceo (provavelmente a partir do Cenomaniano). A cobertura superior, comportando sedimentos do NeoCretáceo e do Cenozóico, mostra como característica principal uma seqüência de episódios de progradação e de erosão intercalados. Na extremidade do platô principalmente, o Terciário Inferior é progradante enquanto o Terciário Superior (pós-Mesoeoceno) afina e desaparece gradualmente. Sob o talude continental, um conjunto de massas caóticas mascaram as estruturas profundas dessa margem continental.

Setor Meridionai Um exemplo típico da margem meridional da Guiné encontra-se na figura 5. Neste setor, em direção à quebra do platô, notamos que os horizontes 


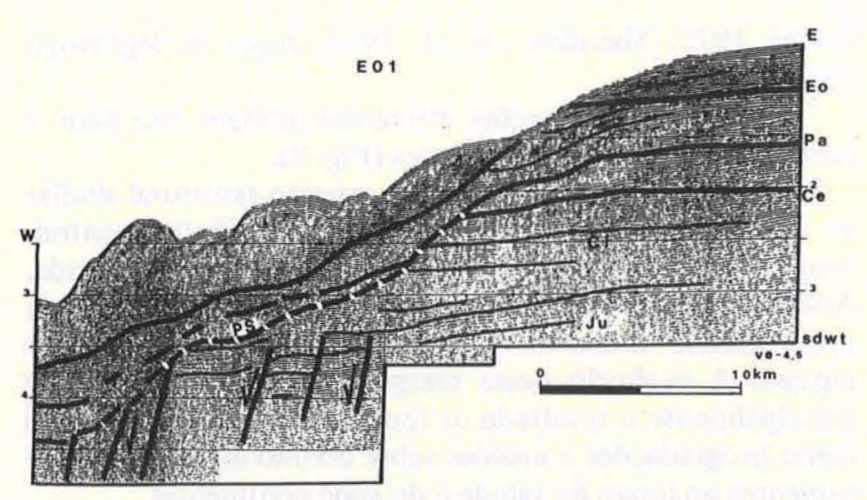

Figura 4 - Seção sísmica típica da margem continental da Guiné (perfil E 01): Eo-teto do horizonte do Eoceno médio; Pa-teto do horizonte do Paleoceno; Ce-teto do horizonte do Cenomaniano; Ju-teto provável dos depósitos do Jurássico. Observamos o paleotude do Neocretáceo recoberto pelos sedimentos do Paleoceno. Escala vertical em segundos tempo duplo (std); ve-exageração vertical

superiores biselam, enquanto os depósitos inferiores chegam a aflorar no alto do talude. Essas duas séries sedimentares são separadas por uma discordância angular evidente. Os sedimentos inferiores, atribuídos ao Eocretáceo mostram-se intensamente falhados enquanto as camadas superiores são sub-horizontais.

No decorrer da campanha Equamarge diversas amostras foram coletadas. O resultado das amostras obtidas por dragagem, sobre os depósitos inferiores aflorantes indica a presença de arenitos azóicos de origem continental. Esses arenitos são similares a certos sedimentos conhecidos no Senegal e na Guiné e datados do Eocretáceo.

A análise dos testemunhos coletados sobre os biséis sedimentares das camadas superiores indica a presença de sedimentos cenozóicos, indo do Eoeoceno e Paleoceno ao Quaternário. Assim sendo, a idade dos diversos horizontes, estabelecida por correlação sísmica, parece ser confirmada. Quanto à discordância principal, ela teria sido certamente formada durante o Cenomaniano ou Turoniano, como indica, aliás, o resultado do poço de perfuração situado em frente a Conacri.

Ainda no setor meridional, a passagem do Platô Marginal à planície abissal de Serra Leoa evidencia a presença de uma zona de fratura (Zona de Fratura da Guiné, Fig. 6). Notamos na realidade a existência de dois taludes que limitam uma grande (e estreita) bacia sedimentar suspensa; o escarpamento ou talude inferior (mais inclinado) se superpõe a uma dorsal do embasamento. Esse contexto estrutural é idêntico ao que ocorre no Golfo da Guiné, entre as zonas de fraturas São Paulo e da Romanche.

Em direção ao oeste, essa dorsal do embasamento parece estar em continuidade com uma série de montes submarinos, subcirculares, que se caracterizam por fortes anomalias magnéticas. Esses relevos são interpretados nesse estudo como domos vulcânicos, preenchendo um sistema complexo de falhas que pertencem à Zona de Fratura da Guiné. Efetivamente, uma das amostras de dragagem coletada sobre um desses domos indica a presença de um basal to de tipo intermediário (Bertrand, com. pess.), o que confirma nossa hipótese.

A bacia oceânica de Serra Leoa (Fig. 7) comporta uma série sedimentar relativamente fina, onde os depósitos

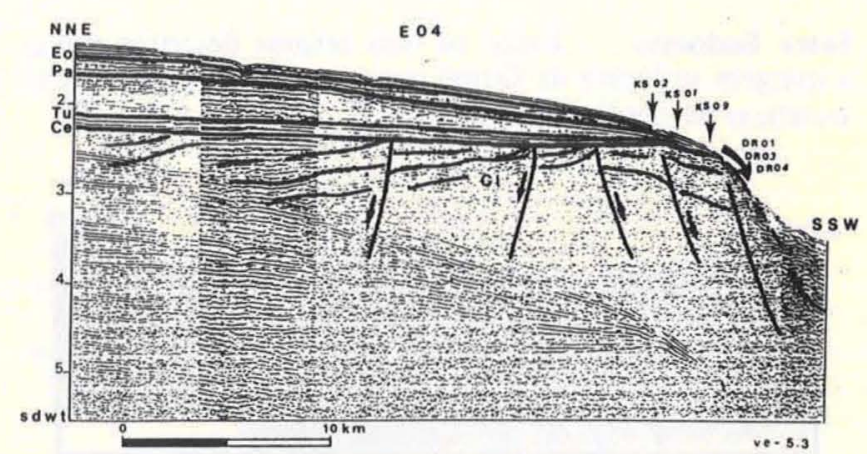

Figura 5 - Seção sísmica típica da extremidade meridional do Platô da Guiné (localização na figura 2). Os símbolos são os mesmos da figura 4, mais Tu-teto do Turoniano. A notar os depósitos profundos atribuidos ao Eocretáceo mergulhando em direção ao norte, cortados por um sistema de falhas e aflorando na extremidade do platô, onde arenitos azóicos foram coletados por dragagem. Observamos também que a cobertura superior afina progressivamente até desaparecer no alto do talude continental. As amostras em testemunho coletadas sobre esses biséis sedimentares indicam como idade para esses depósitos Mesoeoceno a Mioceno com remanejamentos do Paleoceno

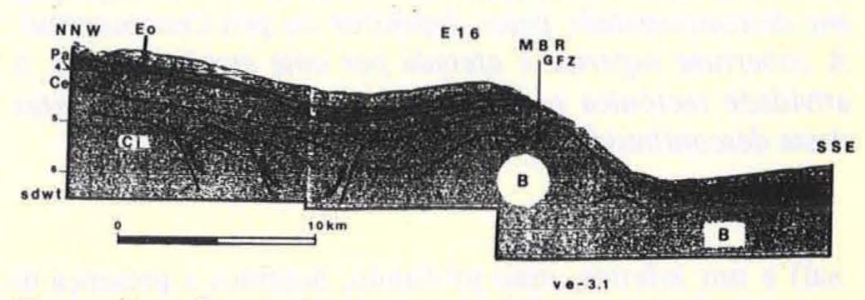

Figura 6 - Seção sísmica típica da margem meridional da Guiné (localização na figura 2). Os simbolos são os mesmos da figura 4, mais DE-dorsal do embasamento; ZFG-Zona de Fratura da Guiné; e SO-substrato oceânico. A notar a dorsal do embasamento associada à Zona de Fratura da Guiné barrando os sedimentos provenientes do norte, concentrados em uma grande bacia sedimentar suspensa, e impedidos de atingir a planicie abissal de Serra Leoa

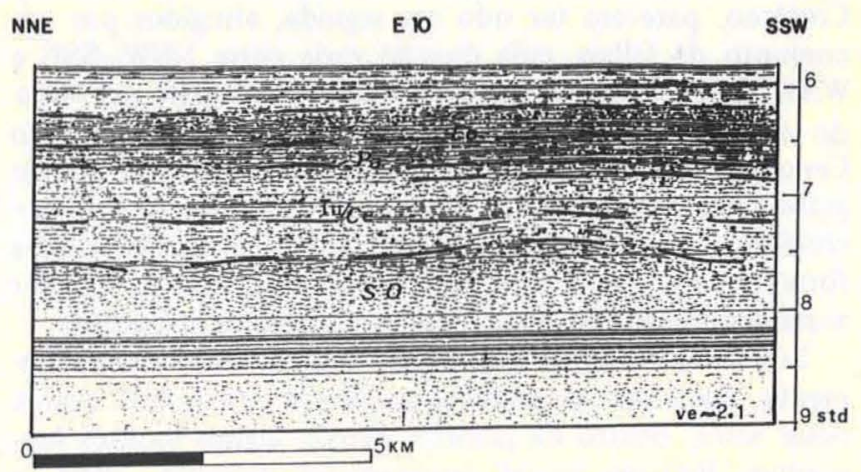

Figura 7 - Seção sísmica da bacia profunda de Serra Leoa (perfil E 10; localização na figura 2). Os simbolos são os mesmos na figura 4, mais SO-substrato oceânico

atribuídos por correlação sísmica ao Eocretáceo parecem cobrir diretamente o assoalho oceânico.

Entre um escarpamento superior (talude do Platô Margi- 
Setor Sudoeste : Entre os dois setores descritos acima, a margem sudoeste da Guiné possui um conjunto de características particulares (Fig. 8).

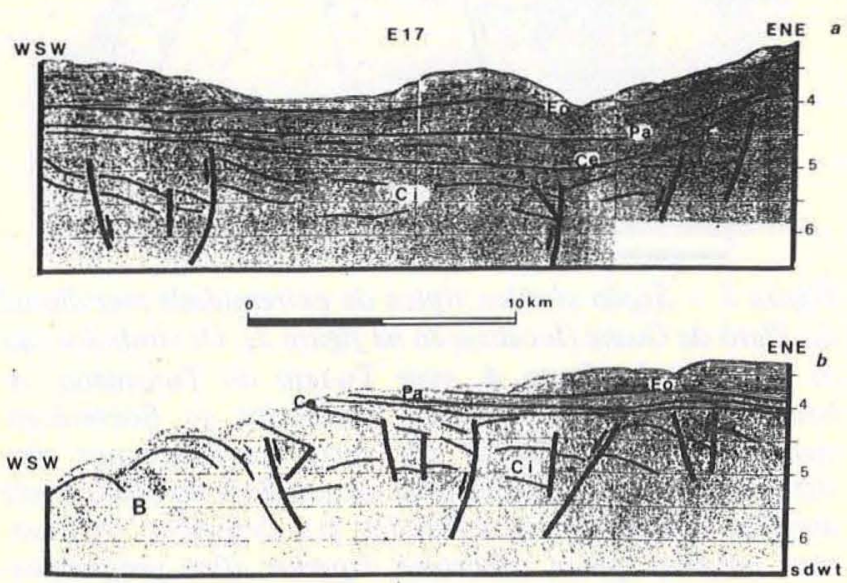

Figura 8 - Duas seções sísmicas extraídas do perfil E 17 (localização na figura 2) através da margem sudoeste da Guiné. Os simbolos são os mesmos das figuras 4 e 6 . Notamos a série sedimentar inferior intensamente fraturada Tatribuida por correlação ao Eocretáceo) e recoberta em descontinuidade pelos depósitos do pós-Cenomaniano. A cobertura superior é afetada por uma erosão intensa. A atividade tectônica parece ter terminado um pouco antes dessa descontinuidade

nal) e um inferior, mais profundo, notamos a presença de uma grande bacia sedimentar, cujo alicerce sísmico corresponde a uma série de blocos estruturais. Esses depósitos inferiores são intensamente fraturados por um conjunto de falhas, com rejeitos variáveis. A eles se superpõe, em discordância, uma cobertura superior formada de camadas subhorizontais, mostrando traços de uma erosão importante e típica desse setor. Os horizontes apresentam as mesmas características sísmicas e parecem ser equivalentes dos depósitos encontrados no Platô Marginal da Guiné.

Os sedimentos inferiores, depositados no início do Cretáceo, parecem ter sido em seguida, atingidos por um conjunto de falhas, cuja direção varia entre NNW-SSE e WNW-ESE. Os movimentos tectônicos cessariam por volta do Albiano tardio, como indica a discordância datada do Cenomaniano ou Turoniano. Posteriormente, esse grande gráben parece ter sido recoberto pelos seidmentos do Neocretáceo e do Cenozóico, submetidos em seguida a uma forte erosão. Um dos resultados dessa erosão parece ser atualmente o afloramento local dos depósitos inferiores.

Sob o talude inferior encontra-se uma dorsal do embasamento, que parece estender-se em direção a noroeste. Ainda nesse setor, dentro da planície abissal, alguns montes sub. marinos limitam bacias sedimentares estreitas, onde, a exemplo da margem meridional, nota-se uma cobertura sedimentar fina cobrindo o substrato oceânico.

INTERPRETAÇÃO ESTRUTURAL DO PLATÕ MARGINAL DA GUINÉ O Platô Marginal da Guiné constitui, sem dúvida, uma extensão do embasamento continental da África ocidental, recoberto de sedimentos paleozóicos, mesozóicos e cenozóicos (Templetom 1971, Lehner \& De
Ruiter 1977, Sheridan et al. 1969, Jones \& Mgbatogu 1982).

Três taludes de direções diferentes limitam esse platô e caracterizam três setores distintos (Fig. 9).

$O$ setor ocidental apresenta um aspecto estrutural similar ao das margens continentais do Oceano Atlântico central, como, por exemplo, as margens do Marrocos e da Flórida. Atualmente, as estruturas distensivas encontram-se em profundidade mascaradas por uma cobertura sedimentar espessa. A evolução dessa margem durante o Terciário é principalmente o resultado de fenomenos sedimentares, tais como progradações e erosões sobre o Platô Marginal e deslizamentos ao longo do talude e do sopé continental.

Este setor é classificado neste estudo como um trecho da margem continental oeste africana, formada no Jurássico, em conseqüência da separação da América do Norte da Âfrica.

A margem meridional da Guiné possui um aspecto estrutural diferente, em relação aos movimentos transformantes da Zona de Fratura da Guiné. Os sedimentos terrígenos depositados no Eocretáceo sofream tectonismo e afloram na extremidade do Platô Marginal. Esses depósitos são selados por uma discordância angular, seguida de uma série de camadas sub-horizontais que biselam na extremidade do Platô. O talude continental encerra uma grande bacia sedimentar, cujo limite inferior se superpõe a uma dorsal do embasamento, típica de margens traniscorrentes (tipo marginal basement ridges). Dentro da planície abissal notamos a presença de inúmeros domos, coincidindo com anomalias magnéticas e interpretadas como edifícios vulcânicos.

Essa margem é associada aos movimentos transformantes da Zona de Fratura da Guiné, responsáveis pela criação de um sistema de falhas em escalonamento, estas por sua vez, preenchidas por uma série de vulcões submarinos.

$O$ setor intermediário ou margem sudoeste da Guiné mostra ao mesmo tempo heranças dos dois tipos de estruturações precedentes. Um sistema de fraturas em leque parece ter arrancado uma parte do Platô Marginal da Guiné, originando assim uma grande bacia, onde os sedimentos inferiores conservam os traços desse estiramento.

Esse setor é interpretado como uma porção da margem jurássica da Guiné, que foi tectonicamente reativada durante os movimentos transformantes da Zona de Fratura da Guiné. Esse deslocamento lateral destro gerou um sistema de falhas em leque ou estruturas tipo "Riedell". Se essa idéia for correta, a dorsal do embasamento situada sob o escarpamento inferior, nesse setor, poderá ser associada a uma paleozona de fratura do Oceano Atlântico central. Essa hipótese concorda com o modelo de evolução desse oceano, proposto recentemente por Klitgord \& Schouten (no prelo) e com o modelo de Pindell (1985).

DISCUSSÃo E CONCLUSÃo As interpretações estratigráficas e estruturais sintetizadas anteriormente, permitem distinguir duas fases de evolução da área:

- A primeira, no Jurássico, corresponde à formação da margem ocidental da Guiné, cujos atuais aspectos sedimentares e estruturais evidenciam uma relação direta com a formação do Oceano Atlântico central.

- A segunda, ocorrente durante o Eocretáceo representa os movimentos transcorrentes da Zona de Fratura da Guiné e a formação consecutiva da margem meridional da Guiné. Ao mesmo tempo, uma parte da margem jurássica criada anteriormente seria reativada. $\mathrm{O}$ efeito dessa fase 


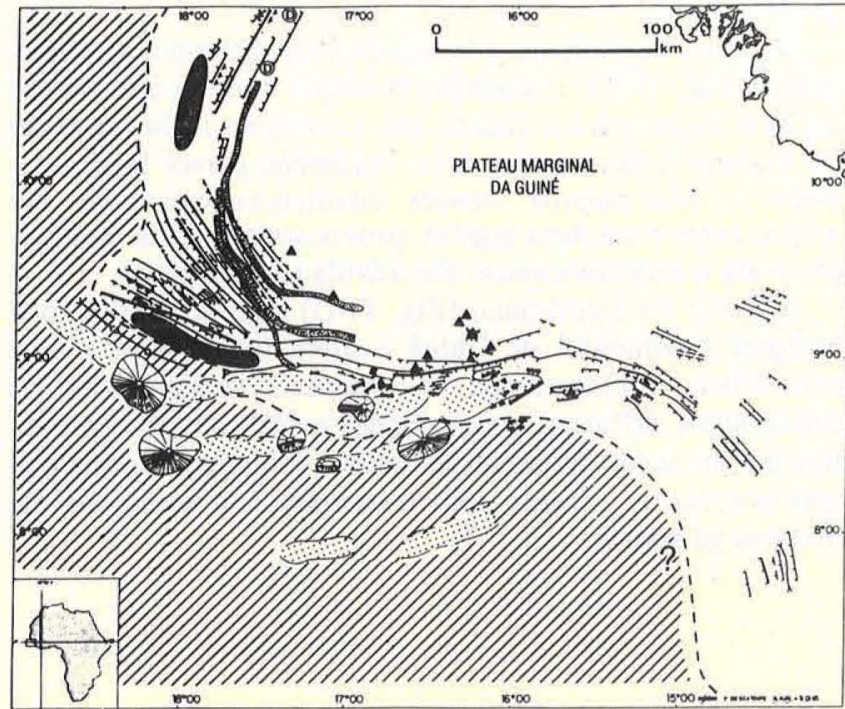

- falhas com rejeito superior a $500 \mathrm{~m}$

- falhas com rejeito inferior a $500 \mathrm{~m}$

$\longrightarrow$ - eixos das bacias sedimentares principais

$\Delta \Delta-$ manifestações vulcânicas intra-sedimentares

שIIID - dorsais do embasamento, marginais

I.:-dorsais do embasamento de origem provavelmente vulcânica

-domos vulcânicos

-zonas de afloramento ou subafloramento. Do alto ao baixo, em direçäo ao talude, afloramentos do Mesoeoceno, do Neocretáceo e do Eocretaceo.

$D D$ - diápiros de sal

[TT - limite continente-oceano baseado em observações sismicas

Figura 9 - Mapa estrutural esquemático da margem guineana

tectônica no setor sudoeste parece ter sido a reorganização das estruturas existentes e a criação de novas estruturas complexas.

Nessa hipótese, a margem guineana teria representado a extremidade meridional do Atlântico central, quando no decorrer do Eocretáceo, foi submetida a uma reativação tectônica, em relação à expansão do Oceano Atlântico Sul e com os movimentos conseqüentes da Zona de Fratura da Guiné.

Nas diversas reconstituições do Oceano Atlântico (Bullard et al. 1965, Le Pichon \& Fox 1971, Olivet et al. 1984), a margem guineana é considerada em sua totalidade como fazendo parte do Oceano Atlântico central. Sua região homóloga é indicada como sendo a região da FlóridaBahamas enquanto a Zona de Fratura da Guiné seria equivalente de uma zona de fratura chamada Zona de Fratura das Bahamas. Essa idéia supõe que a margem meridional da Guiné e a planície abissal de Serra Leoa façam parte do Atlântico central o que não parece ser confirmado pelos resultados desse estudo. Segundo nossa interpretação sísmica, a bacia de Serra Leoa não parece comportar sedimentos mais antigos que o Eocretáceo.

Na reconstrução proposta por Bullard et al. (1965), a margem meridional da Guiné situa-se em frente a um vazio oceânico que até recentemente não podia ser explicado. Na realidade, a dificuldade em encontrar a região homôloga da margem sul-guineana vem da falta de conhecimento em relação à evolução do Caribe, difícil de ser estudada até então, nos atuais modelos da tectônica de placas. No entanto, dois modelos propostos recentemente (Klitgord \& Schouten, no prelo, Pindell 1985) permitem uma melhor compreensão global do desenvolvimento dessa região no contexto do Oceano Atlântico Centro-equatorial. Ambos os modelos confirmam que a margem ocidental da Guiné é homóloga à região Flórida-Bahamas. Além disso, esses autores evocam a presença de uma zona de fratura atravessando a Flórida, que poderia ser associada, do lado da Guiné, à dorsal do embasamento situada sob o escarpamento inferior, no setor sudoeste.

A originalidade desses dois modelos consiste na justaposição da margem meridional da Guiné com a margem setentrional do platô profundo do Demerara, situado entre o Brasil e a Guiana.

Baseados nos resultados de nosso estudo, que ratificam essa proposição, podemos cogitar que o Platô da Guiné e o Platô do Demerara constituíram no passado uma só região.

A fim de estabelecer um esquema evolutivo da região, utilizamos o modelo proposto por Klitgord \& Schouten (no prelo), que foi adaptado à área estudada. Partindo dos mesmos parâmetros que esses autores, obtivemos a situação inicial das duas regiões e quatro etapas principais que representam a evolução da margem guineana.

Por volta do Mesojurássico (Fig. 10), o Oceano Atlântico central encontra-se ainda fechado e a Guiné é conectada a oeste com a Flórida. Essa posição está de acordo com os dados geológicos e geofísicos conhecidos nas duas regiões. Esta reconstituição mostra, de uma maneira geral, uma boa justaposição dos três continentes, com exceção de algumas áreas de recobrimento, que localmente seriam o resultado de uma construção sedimentar posterior, como é o caso do delta do Amazonas, no Brasil, e da Bacia Sedimentar de Aioum-Tarfaya, no noroeste da África. Em outros trechos, esse recobrimento parece indicar uma aproximação um pouco exagerada dos continentes.

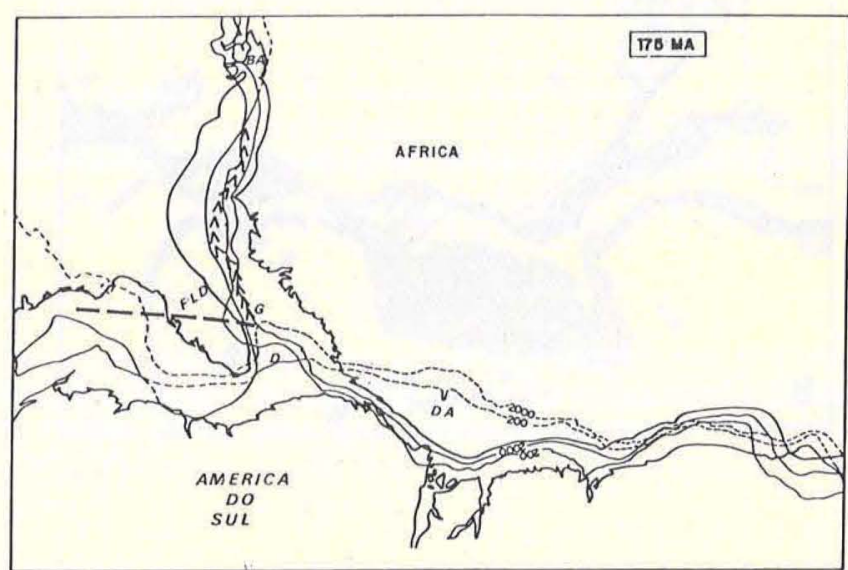

Figura 10 - Reconstituição dos continentes antes da abertura do Oceano Atlântico, utilizando os parâmetros estabelecidos por Klitgord \& Schouten (no prelo). Notamos o Platô da Guiné justaposto ao Platô da Demerara. Em volta de $175 \mathrm{Ma}$, um rifte começa a se instalar entre a África e a América do Norte e se estende em direção ao sul até a descontinuidade da Flórida e o centro do Platô da Guiné. G, Guiné; D, Demerara; DA, delta do Amazonas; BA, Bacia de Aioum-Tarfaya; e FLD, Flórida. Contornos batimétricos de 200 e 2.000 m utilizados como limites continentais 
O primeiro esquema evolutivo (Fig. 11-A) mostra, no início do Cretáceo, uma abertura precoce do Oceano Atlântico central formando uma larga bacia, contornada pela região Guiné-Demerara.

Provavelmente durante o Barremiano (Fig. 11-B), os primeiros movimentos cisalhantes do Atlântico Equatorial atingem a região, que começa a se dividir; o platô do Demerara desliza progressivamente ao longo da Zona de Fratura da Guiné. Esse movimento gera um sistema complexo de falhas atingindo as duas futuras margens continentais. Do lado da Guiné, esse processo de fratura intenso e particular permite a ascendência de um magma abundante, atingindo toda a extremidade meridional do Platô.

Simultaneamente a esses movimentos transcorrentes e oblíquos ao eixo do Atlântico, a margem oriental do Demerara diverge progressivamente da atual margem continental de Serra Leoa.

No final do Albiano e início do Cenomaniano, provavelmente (Fig. 11-C), o assoalho oceânico começa a se formar entre o Demerara e a Guiné, em conseqüência da expansão do Oceano Atlântico Sul. Esse fenômeno parece ter ocasionado o relaxamento tensões cisalhantes existentes até então, entre essas duas regiões, provocando assim a diminuição e até o estacionamento das atividades tectônicas.

A partir do Santoniano (Fig. 11-D) e até o Cenozóico, a margem continental da Guiné é submetida apenas a uma subsidência, acompanhada de fenômenos sedimentares. As construções deltaicas, progradações e deslizamentos predominam no setor ocidental enquanto fenômenos principalmente erosivos atingem toda a extremidade meridional da margem guineana.
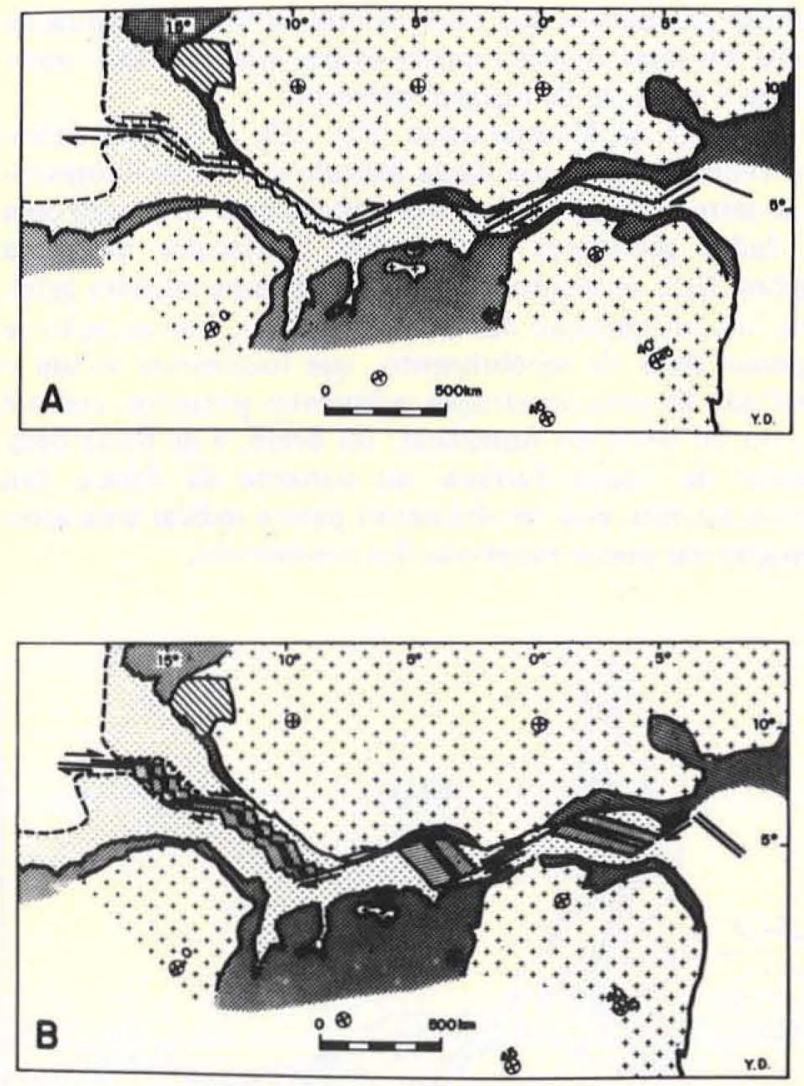
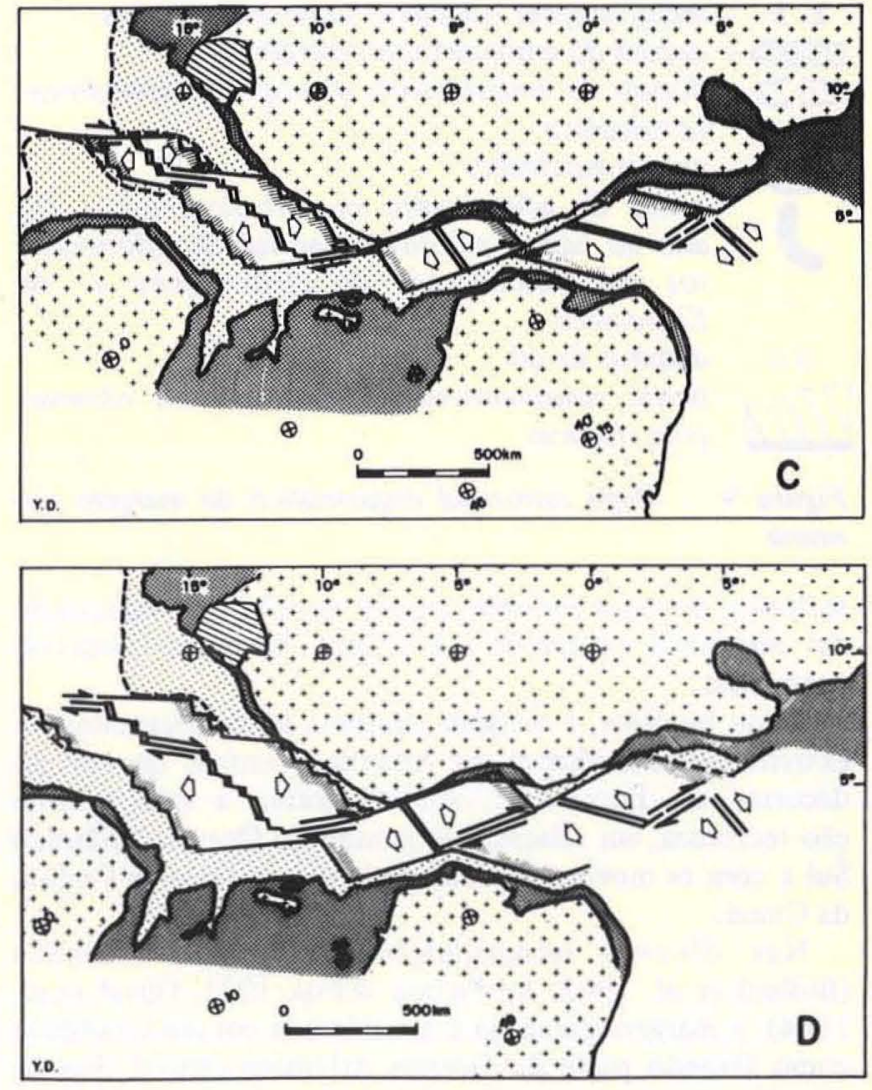

Figura 11 - Modelo de abertura proposto. A- Reconstrução para 133 Ma (utilizando os mesmos parâmetros de Klitgord \& Schouten no prelo). A América do Norte encontra-se separada da África ocidental, enquanto o Atlântico equatorial encontrase ainda fechado. B- A situação dos continentes há $116 \mathrm{Ma}$ (Barremiano). Nesta fase, os setores de margens divergentes começam a se separar e provavelmente as primeiras tensões cisalhantes a afetar os setores oblíquos ao eixo de abertura do Oceano Atlântico. C- A posição dos continentes por volta de $100 \mathrm{Ma}$ (Albo-Cenomaniano), extrapolada do modelo de Klitgord \& Schouten (no prelo). Esta fase corresponde à separação inicial do Demerara da Guiné. O Platô do Demerara desliza ao longo da Zona transformante da Guiné e provavelmente já existiria nessa época uma fina crosta oceânica entre as duas regiōes. DPor volta de $80 \mathrm{Ma}$, o relaxamento das tensões cisalhantes parece ter provocado uma aceleração da expansão oceânica devido também ao fim do contato continente-continente e da junção das duas dorsais oceânicas (do Atlântico Norte e do Atlântico Sul) 


\section{REFERÊNCIAS BIBLIOGRAFICAS}

BULLARD, E.; EVERETT, J.E.; SMITH, A.G. - 1965 - The fit of the continents around the Atlantic. In: Symposium of continental drift; Phil. Trans. Royal Soc., London, n. ${ }^{\circ} 258$, p. 41-52.

EGLOFF, J. - 1972 - Morphology of ocean basin seaward of northwest Africa: Canary Islands to Monrovia, Liberia. $\overrightarrow{A m}$. Assoc. Petrol. Geol. Bull., 54:(4):694-706.

EMERY, K.O.; UCHUPI, E.; PHILLIPS, J.; BOWIN, C.; MASCLE, J. - 1975 - The continental margin off western Africa: Angola to Sierra Leone. Am. Assoc. Petrol. Geol. Bull., 59(12):2209-2265.

JONES, E.J.W. \& MGBATOGU, C.C.S. - 1982 - The structure and evolution of the west african continental margin off Guinea. Guinea Bissau and Sierra Leone. In: The Ocean Floor; SCRUTTONN, R.A. \& TALWANI, M. eds. The Ocean Floor. John Wiley \&Sons Ltd.), 318 p., 3 mapas, p. 165-202.

KLITGORD, K.D. \&SCHOUTEN, H. (no prelo) - Plate kinematics of the Central Atlantic. In: TUCHOLKE, B.E. \&VOGT, P.R. eds. The Geology of North America: the western Atlantic region. Geol. Soc. Am., v. M, p. 351-378. (DNAG Series).

KRAUSE, D.C. - 1964 - Guinea fracture Zone in the Equatorial Atlantic. Science, 146(3640):57-59.

LEHNER, P. \& DE RUITER, P.A.C. - 1977 - Structural history of the Atlantic margin of Africa. Am. Assoc. Petrol. Geol. Bull., 61(7):961-981.
LE PICHON, X. \& FOX, J.P. - 1971 - Marginal offsets fracture zones and the early opening of the North Atlantic. Journ. Geophys. Res., 76(26):6294-6308.

OLIVET, J.L.; BONNIN, J.; BEUZART, P.; AUZENDE, J.M. 1984 - Cinématique de l'Atlantic Nord et Central. Publications du Centre National pour l'Exploitation des Océans (CNEXO); Rapports Scientifiques et Techniques, n. ${ }^{\circ}$ 54, 108 p., 8 pranchas.

PINDELL, J.L. - 1985 - Alleghenien reconstruction and subsequent evolution of the Gulf of Mexico, Bahamas, and Proto-Caribbean. Tectonics, 4(1):1-39.

SHERIDAN, R.E.; HOUTZ, R.E.; DRAKE, C.L.; EWING, M. 1969 - Structure of continental margin off Sierra Leone, West Africa. Jorn. Geophys. Res., 74(10):2512-2530.

TEMPLETON, R.S.M. - 1971 - The Geology of the continental margin between Dakar and Cape Palmas. Inst. Geol. Sci. Rep., 70(16):43-60.

UCHUPI, E.; EMERY, K.O.; BOWIN C.; PHILLIPS, J.D. - 1976 Continental margin off western Africa: Senegal to Portugal. Am. Assoc. Petrol. Geol. Bull., 60(5):809-879.

MANUSCRITO 404

Recebido em 30 de outubro de 1986 Revisão aceita em 27 de abril de 1987

"Eu tenho grando respeito pelos geofísicos, mas não posso esquecer que, quando eu era estudante, eles diziam que a deriva continental era impossível. Agora eles parecem tomar toda a glória por isso como se tivesse sido idéia deles em primeiro lugar. 